\title{
The Experience of Using Innovative Artificial Filter Arrays on South Kuzbass Open Pit: Case Study
}

\author{
Maxim Tyulenev ${ }^{1, *}$, Yury Lesin $^{1}$, Ekaterina Tyuleneva ${ }^{1}$ and Elena Murko ${ }^{1}$ \\ ${ }^{1}$ T. F. Gorbachev Kuzbass State Technical University, 650000, 28 Vesennyaya st., Kemerovo, \\ Russian Federation
}

\begin{abstract}
The article describes the detailed example of placement of artificial filter arrays in one of Kuzbass open pits. It is proved that the use of the existing rock dump as an artificial filter array allows cleaning the quarry wastewater to the required parameters. Therefore, for water purification, it is possible to pile a new array as well as to use the existing dump, which will reduce the operating costs and the land consumption of open pit mining operations. Also, a brief methodology for determining the parameters of the artificial filter array is given in the article, taking into account the volume of contaminated water, the degree of its contamination and the location of the filter. The proposed complex of measures significantly improves the geo-ecological situation of mining region.
\end{abstract}

\section{Introduction}

Main geoecological problems of Kemerovo region are:

- every year the water bodies of region receive about 2 billion $\mathrm{m}^{3}$ of quarry water;

- more than 500 million $\mathrm{m}^{3}$ of water coal enterprises discharge without any treatment;

- aggregate weight of pollutants reaches more than 600 thousand tons;

- the main polluting substances in quarry waste water are suspended solids (finelydispersed rock and coal particles);

- the concentration of suspended solids in quarry water is up to $250 \mathrm{mg} / 1$, in some cases 2000-3000 mg / 1, which exceeds maximum permissible concentrations (MPC) in many times.

Therefore the solution of these problems must take into account the following factors:

- continuous toughening of requirements for quality of waste water discharge;

- the use of holding and clarifying ponds does not provide quarry waste water

purification according to MPC;

- existing treatment facilities occupy considerable areas;

- catchments basins are distantly located from each other and change location in the process of mining.

\footnotetext{
${ }^{*}$ Corresponding author: tma.geolog@kuzstu.ru
} 


\section{Material and method}

Calculation of the water intake consists in checking the ability of the drainage pipe of a given length and diameter to pass the entire flow of water being purifyed. Preliminarily we take the drainage pipe length $L_{t}=5 \mathrm{~m}$ and the diameter $2 r_{t}=0.5 \mathrm{~m}$.

Considering the filtration flow around the drainage pipe as flat-radial, and neglecting the gravitation, the differential equation characterizing the water consumption at a distance $r$ from the pipe can be written as:

$$
q=-2 * \pi * r * k \frac{d h}{d r}
$$

where: $q$ - the flow of liquid per $1 \mathrm{~m}$ of the length of the drainage pipe ; $q=Q / L_{n}, Q$ is the productivity of purifying facilities; $L_{n}$ - the reduced length of the drainage pipe, considering its walls water-permeable, $\mathrm{m} ; k$ - the rate of filtration; $h$ - the value of the liquid head at a distance $r$ from the pipe.

The solution of the differential equation is reduced to the separation of variables with subsequent integration. As a result, we obtain the following formula:

$$
q=\frac{2 * \pi * k * H}{\ln \frac{R}{r}}
$$

where: $H$ - the amount of pressure the of liquid in the drainage pipe; $r_{t}$ - the radius of drenage pipe, $\mathrm{m} ; R$ - the radius of the drainage trench filling is equal to the distance from the center of the pipe to the walls of the trench, $m$.

Taking the value of $q$ from formula (2), the reduced length of the drainage pipe is:

$$
L_{n}=Q / q
$$

The calculated pipe lengh $L_{t r}$ in this case can be calcelated as:

$$
L_{t r}=k_{n} \cdot L_{n}
$$

where: $k_{n}$ - the rate considered the presence of perforations.

The coefficient $k_{n}$ can be found as the ratio of the surface area of the drainage pipe to the total area of the perforations.

When the capacity of water treatment plants $Q$ is $500 \mathrm{~m}^{3} /$ day, the filtration rate is 0.01 $\mathrm{m} / \mathrm{s}$ and the pipe diameter $2 r_{t}=0.5 \mathrm{~m}$, we find that $L_{m}=5 \mathrm{~m}>L_{t r}$. Consequently, the given dimensions of the drainage pipe and the trench ensure the passage of all water entering the purifying.

\section{Results and Discussion}

The choice of the location of the water intake and the calculation of water filtration in the dump massif must be besed on the mutual location of open pit office and the rock dump, the configuration of the dump and the relief of the underlying surface. The optimal location is near the point indicated on open pit mining plan (Fig. 1). 


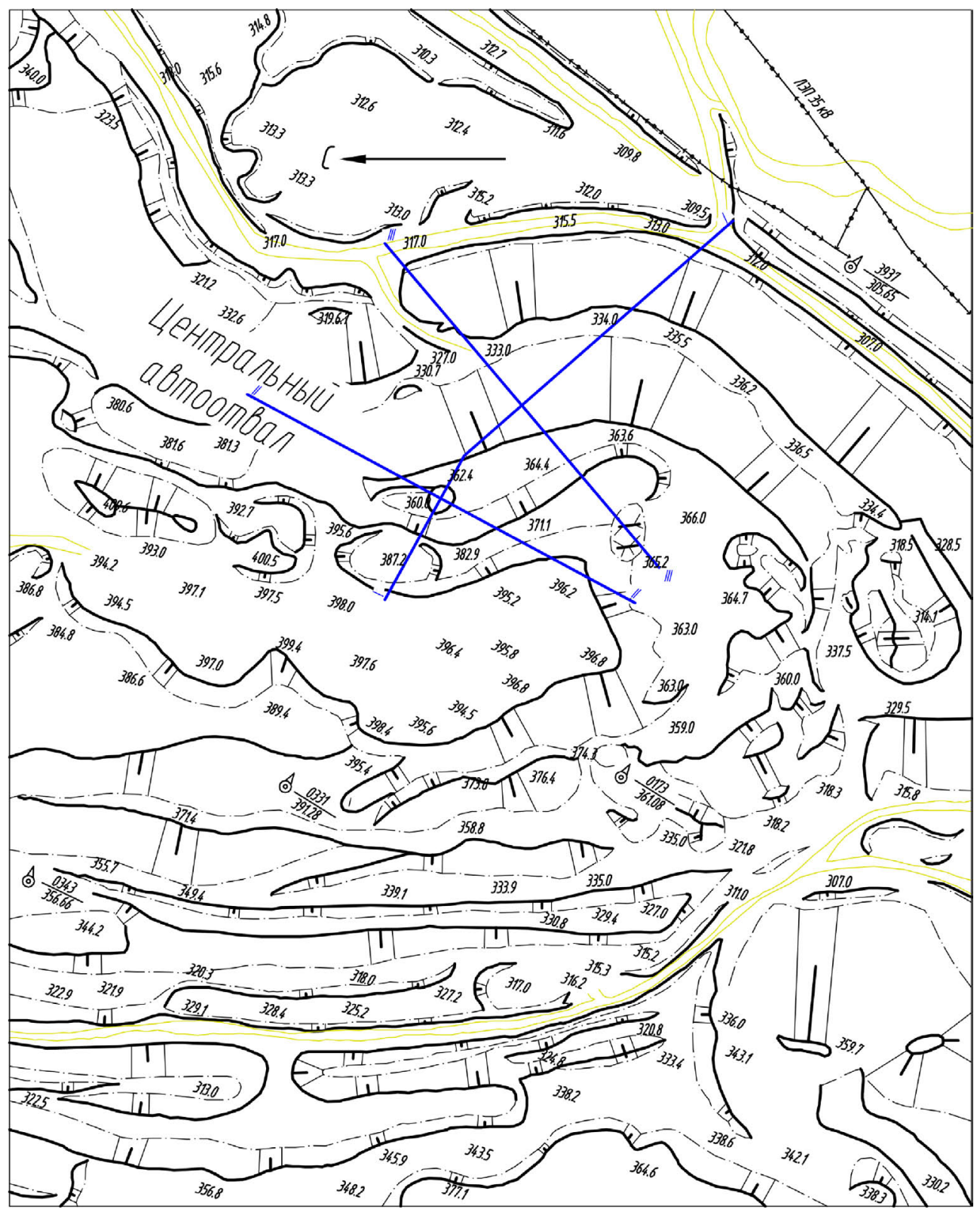

Fig. 1. The location of the water intake

According to the plan of the underlying surface (Fig. 2), we determined the likely direction of the water filtered in the dump, and found the point of seepage of purified water from the dump. The probable direction of water movement in the dump is shown in Fig. 3 by the dotted line. The place of water seepage is located as the point of intersection of line I-I with the line of the lower contour of the slope of the first tier of the dump. 


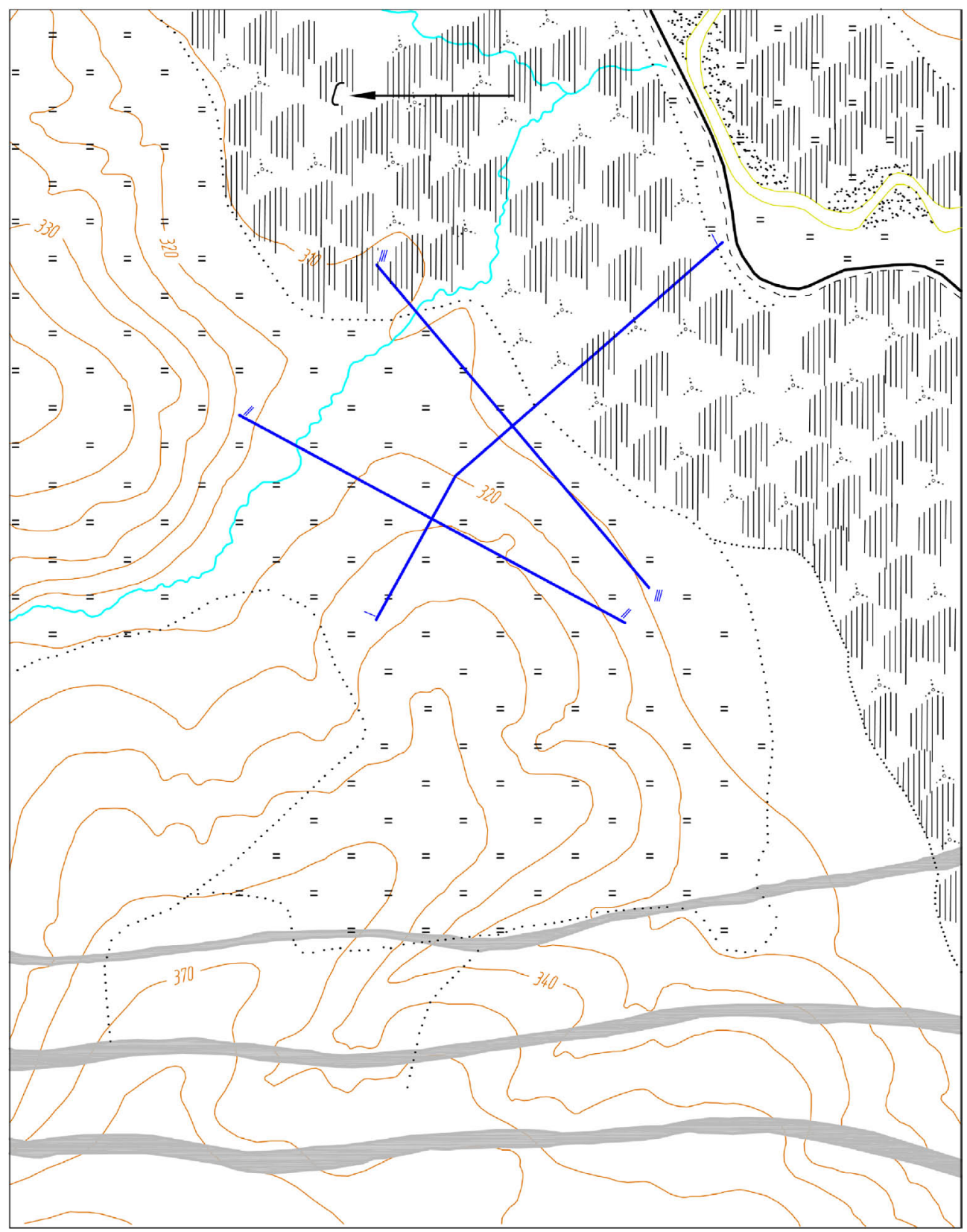

Fig. 2. The plan of the underlying surface

The longitudinal and transverse profiles of the rock dumps are shown in Fig. 3. The scale of the plans was adopted 1: 5000, profiles 1: 2000 . 


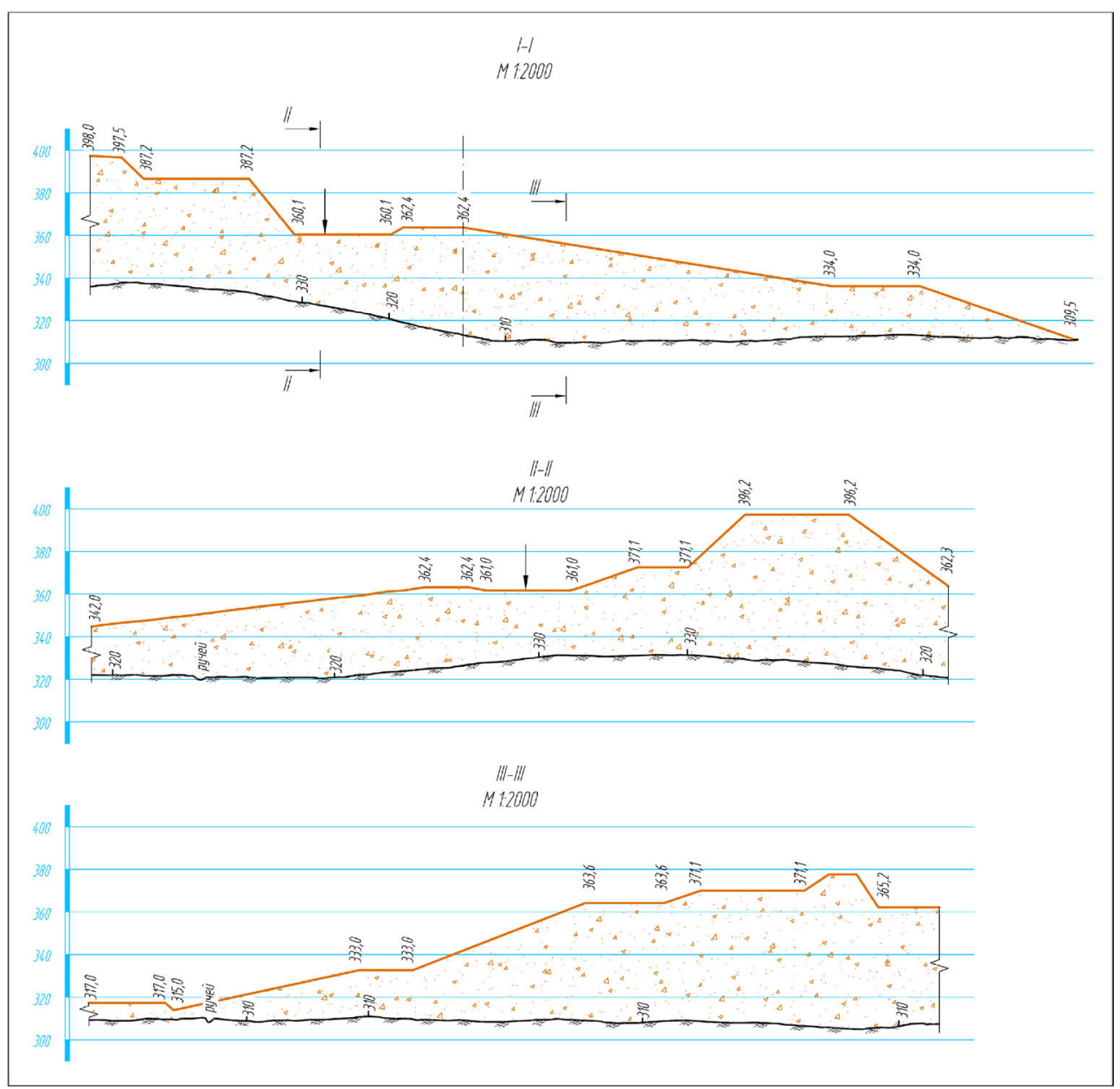

Fig. 3. The longitudinal and transverse profiles of the rock dumps

The distance between water entry and exit points of the dumps is $340 \mathrm{~m}$.

When filtering contaminated water in lump rock massifs, sediments are suspended in the pores and the water is purified. This is due to the process of natural penetration or artificial insertion of small particles into rock's fractures - colmatation process [1-6].

It was found that the following dependence between the concentration of suspended solids $C$ and the length of water filtration in the dump $L$ there can be expressed as (2):

$$
C=C_{0} \exp (-\eta L)
$$

where: $C_{o}-$ initial consentration of suspended solids;

$\eta$ - filtering index.

The filtering index $\eta$ depends on the size of the components of the filtering array, its petrographic composition, water filtration rate and other factors.

For rock dumps and other arrays from bedrock rocks of Kuzbass open pit it was found within 0.005-0.05.

Calculations using formula (5) showed that with an initial suspended matter concentration of $380 \mathrm{mg} / \mathrm{l}$, the filtration length $L=340 \mathrm{~m}$ and a filtering index of 0.035 , the concentration of suspended solids in purified water does not exceed $1 \mathrm{mg} / \mathrm{l}$. 
In this case the filtration calculation of the rock dump for the passage of all water entering the treatment is not needed, because the calculation of the water intake is performed.

\section{Conclusion}

Thus, for the chosen location of the water intake on the dump and the distance between the entry and exit points of water from the dump (equal to $340 \mathrm{~m}$ ), the necessary degree of wastewater treatment from polluting suspended solids is provided.

\section{References}

1. S.L. Arnon, P. Marx, K.E. Searcy, A.I. Packman, Hydrol. Proc., 24, 108 (2010)

2. T. Esakkimuthu, D. Sivakumar, S. Akila, Poll. Res., 33, 567 (2014)

3. S.K. Gupta, K. Ramesh, S. Sameer, Poll. Res., 34, 111 (2015)

4. J.I. Jones, J.F. Murphy, A.L. Collins, D.A. Sear, P.S. Naden, P.D. Armitage, Res. Appl., 9, 67 (2011)

5. D.L. Karwan, J.E. Saiers, Water Resour. Res., 48, 15 (2012)

6. M.M. Sharma, Y.C. Yortsos, AlChE J., 33, 1636 (1987) 